\title{
Skin-scale genetic structure of Sarcoptes scabiei populations from individual hosts: empirical evidence from Iberian ibex-derived mites
}

\author{
S. Alasaad \& D. Soglia \& M. Sarasa \& R. C. Soriguer \& \\ J. M. Pérez \& J. E. Granados \& R. Rasero \& X. Q. Zhu \& \\ L. Rossi
}

\begin{abstract}
The objective of the present study was to examine the extent of genetic diversity among Sarcoptes scabiei individuals belonging to different skin subunits of the body from individual mangy hosts. Ten microsatellite primers were applied on 44 individual S. scabiei mites from three mangy Iberian ibexes from Sierra Nevada Mountain in Spain. Dendrograms of the mites from the individual Iberian ibexes,
\end{abstract}

S. Alasaad ${ }^{\prime}$ M. Sarasa $:$ J. M. Pérez

Departamento de Biología Animal, Biología Vegetal y Ecología, Universidad de Jaén,

Campus Las Lagunillas, s. n.,

23071 Jaen, Spain

S. Alasaad $\because$ D. Soglia $\because$ R. Rasero $:$ L. Rossi $(\star)$

Dipartimento di Produzioni Animali, Epidemiologia ed Ecologia, Università di Torino,

Via Leonardo da Vinci 44,

10095 Grugliasco, Italy

e-mail: luca.rossi@unito.it

R. C. Soriguer

Estación Biológica de Doñana,

Consejo Superior de Investigaciones Cientificas (CSIC),

Apartado 1056,

41080 Sevilla, Spain

J. E. Granados

Espacio Natural de Sierra Nevada,

Carretera Antigua de Sierra Nevada,

$\mathrm{Km} \mathrm{7.5,}$

E-18071 Pinos Genil, Granada, Spain

X. Q. Zhu (*)

College of Veterinary Medicine,

South China Agricultural University,

483 Wushan Street, Tianhe District,

Guangzhou, Guangdong Province 510642,

People's Republic of China

e-mail: xingquanzh@scau.edu.cn showing the proportion of shared alleles between pairs of individual mites representing three skin subpopulations (head, back, and abdomen subunits), allowed the clustering of some mite samples up to their skin subunits. This genetic diversity of S. scabiei at skin-scale did not have the same pattern in all considered hosts: for the first Iberian ibex (Cp1), only mites from the head subunit were grouped together; in the second individual (Cp2), the clustering was detected only for mites from the abdomen subunit; and for the third one (Cp3), only mites from the back subunit were clustered together. Our results suggest that the local colonization dynamics of S. scabiei would have influenced the nonrandom distribution of this ectoparasite, after a single infestation. Another presumable explanation to this skinscale genetic structure could be the repeated infestations. To our knowledge, this is the first documentation of genetic structuring among S. scabiei at individual host skin-scale. Further studies are warranted to highlight determining factors of such trend, but the pattern underlined in the present study should be taken into account in diagnosis and monitoring protocols for studying the population genetic structure and life cycle of this neglected but important ectoparasite.

Introduction

The understanding of the relationship between landscape structure and species biology is the basis of landscape ecology (Manel et al. 2003; Storfer et al. 2007). It can provide information about population functioning which may be valuable cues for management and conservation decisions (Moritz 1994; Coulon et al. 2006). The classical population genetic view of a species range is of a network of randomly mating populations (Wright 1978). However, 
population and behavioral ecologists working at finer scales have long realized that populations usually consist of demes or subgroups of varying degrees of relatedness or co-ancestry as a result of incomplete or sex-biased dispersal (Sugg et al. 1996). Detailed analyses of genetic structure within animal populations have mostly been conducted in species with well-developed social systems (Hughes 1998; Ross 2001a; Coltman et al. 2003). On another scale, ectoparasites are often site specific on the host (e.g., Choe and Kim 1988; Clayton 1991), but such phenomena have not been studied satisfactorily (Crompton 1997).

Historically, genetic studies on Sarcoptes scabiei has been extremely limited, primarily due to the difficulty in obtaining sufficient numbers of individual mites because of the low parasite burden (in ordinary scabies, less than ten organisms can be identified per host; Mellanby 1944) and the lack of an in vitro culture system (e.g., Brimer et al. 1993; Walton et al. 2004), and secondly because of the difficulty in getting adequate amounts of genetic material (due to the high rate of failed reactions; e.g., Walton et al. 1997; Berrilli et al. 2002). Almost all genetic studies on S. scabiei have been to answer the question that has been the subject of an ongoing debate for many years: whether Sarcoptes mites represent different species or whether they are, in fact, monospecific. Other questions that remain unclearly answered include: are S. scabiei from different geographical locations genetically different? Or could they be considered as a single panmictic population? (Burgess 1994; Ochs et al. 1999; Walton et al. 1999; Zahler et al. 1999; Berrilli et al. 2002; Soglia et al. 2007; Gu and Yang 2008).

Usually, infestation by S. scabiei is generated when mites (founder group) are in contact with their host animals (Pence and Ueckermann 2002). If the different genotypes expand with the same efficacy in the different host skin subunits, alleles from the founder group should be distributed randomly in the different subunits of their host animal. Alternatively, if mites disperse unevenly, due to competition or avoidance processes, genetic mosaic should be created, resulting in unrandom genetic structure (Ross 2001b; Kanno and Harris 2002).

Recent theoretical and empirical studies have demonstrated that disease spread is often more complex than predicted by simple diffusion models (see Hastings et al. 2005 for a review). Nevertheless, to the best of our knowledge, no study was done to investigate the extent of genetic structure in S. scabiei subpopulations regarding the different subunits of the mangy skin from individual hosts (skin-scale). Therefore, the objective of the present study was to examine the genetic structure of S. scabiei populations at host skinscale to test the hypothesis of the random genetic distribution of Sarcoptes mite.

Materials and methods

Iberian ibex-derived S. scabiei

Iberian ibex (Capra pyrenaica) is a natural host for S. scabiei (Pérez et al. 1997, 2002), with high prevalence (up to 50\%) of mangy animals (Alasaad et al. 2008a). For this study, we used three mangy males of Iberian ibex, culled for management purpose in Sierra Nevada Mountain in Southern Spain. The three animals were coded as Cp1, Cp2, and Cp3.

\section{Collection of S. scabiei samples}

A total of $44 \mathrm{~S}$. scabiei mites were collected from the skin of three culled Iberian ibexes: 14 from Cp1, 16 from Cp2, and 14 from Cp3 (Table 1 and Fig. 1). Mites from each individual skin were divided into three subpopulations, namely head subunit $(\mathrm{H})$, back subunit (B), and abdomen subunit (A). The reason behind that was because these three skin subunits: (1) differed according to the timing of the parasitic progression in the host (Pence and Ueckermann 2002); (2) could be the first to contract the ectoparasite (León-Vizcaíno et al. 1999); and (3) because of the large

Table 1 Host animal and skin-subunits used in this study, together with the total/useful number of Sarcoptes mite samples

\begin{tabular}{|c|c|c|c|c|c|c|}
\hline Codes & Animal and code & & Skin subunit and $\mathrm{cc}$ & & Total no. of parasites & No. of useful parasites \\
\hline Сp1H & \multirow[t]{3}{*}{ Capra pyrenaica } & \multirow[t]{3}{*}{ Cp1 } & Head subunit & $\mathrm{H}$ & 4 & 3 \\
\hline Сp1B & & & Back subunit & B & 5 & 3 \\
\hline Cp1A & & & Abdomen subunit & A & 5 & 3 \\
\hline $\mathrm{Cp} 2 \mathrm{H}$ & \multirow[t]{3}{*}{ Capra pyrenaica } & \multirow[t]{3}{*}{ Cp2 } & Head subunit & $\mathrm{H}$ & 5 & 3 \\
\hline Ср2B & & & Back subunit & B & 6 & 3 \\
\hline Cp2A & & & Abdomen subunit & A & 5 & 3 \\
\hline Ср3Н & \multirow[t]{3}{*}{ Capra pyrenaica } & \multirow[t]{3}{*}{ Cp3 } & Head subunit & $\mathrm{H}$ & 4 & 3 \\
\hline Ср3В & & & Back subunit & B & 6 & 3 \\
\hline Сp3A & & & Abdomen subunit & A & 4 & 3 \\
\hline
\end{tabular}




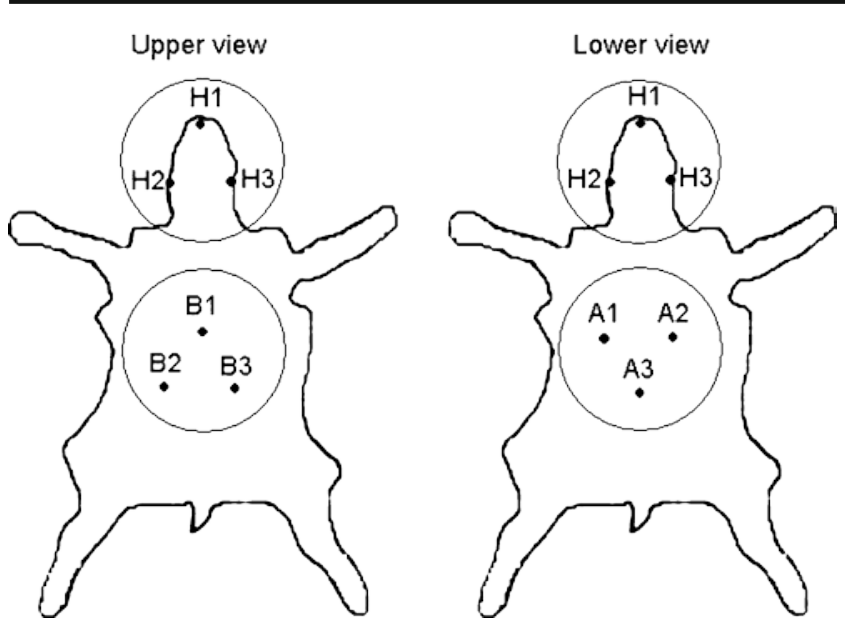

Fig. 1 Drawing showing approximate sites for Sarcoptes mite collection from three skin subunits of Iberian ibex. Codes next to the drawings represent the sample codes in Table 1

distance between each other, which could facilitate the detection of the expected skin-scale genetic diversity. Back and abdomen subunits were circular areas of approximately $400 \mathrm{~cm}^{2}$ each, while all head surface formed the head subunits.

Mites were collected by the wet scraping of the mangy skin using distilled water. The scrapings were made by a scalpel or similar bladelike tool on Petri plates. This step was followed by mite collection using dissecting microscope. Mites were identified as S. scabiei according to the morphological criteria of Fain (1968).

\section{Preparation of S. scabiei genomic DNA}

As described previously (Alasaad et al. 2008b), HotSHOT Plus ThermalSHOCK technique was applied to prepare the DNA for all single S. scabiei mites in this study. Aiming to study the possible intrapopulation polymorphisms, all of the DNA samples were prepared from individual S. scabiei mites.

Fluorescent-based polymerase chain reaction analysis of microsatellite DNA

From the panel described by Walton et al. (1997), ten microsatellites (Sarms 33, 34, 35, 36, 37, 38, 40, 41, 44, and 45) were selected and applied with one multiplex 10× polymerase chain reaction (PCR) as reported by Soglia et al. (2007). Each $15 \mu$ l PCR reaction mixture consisted of $3 \mu \mathrm{l}$ of the single mite DNA, together with the PCR mixture containing all primer pairs (ranged from 0.04 to $0.1 \mu \mathrm{M}$ per primer), $200 \mu \mathrm{M}$ of each dATP, dCTP, dGTP, and dTTP, $1.5 \mu \mathrm{l}$ of $10 \times$ PCR buffer $(200 \mathrm{mM} \mathrm{KCl}$ and $100 \mathrm{mM}$ Tris$\mathrm{HCl}, \mathrm{pH}$ 8.0), $1.5 \mathrm{mM} \mathrm{MgCl}$, and $0.15 \mu \mathrm{l}$ (0.5 U/reaction) HotStartar Taq (QIAGEN, Milano, Italy). Samples were subjected to the following thermal profile for amplification in a 2720 thermal cycler (Applied Biosystems, Foster City, CA, USA): 15 min at $95^{\circ} \mathrm{C}$ (initial denaturing), followed by 37 cycles of three steps of $30 \mathrm{~s}$ at $94^{\circ} \mathrm{C}$ (denaturation), $45 \mathrm{~s}$ at $55^{\circ} \mathrm{C}$ (annealing) and $1.5 \mathrm{~min}$ at $72^{\circ} \mathrm{C}$ (extension), and a final elongation of $7 \mathrm{~min}$ at $72^{\circ} \mathrm{C}$.

Microsatellite analysis

Using 96-well plates, aliquots of $12 \mu \mathrm{L}$ of formamide with Size Standard 500 Liz (Applied Biosystems, Foster City, CA, USA) and $2 \mu$ l PCR product were prepared. Then, the plates were heated for $2 \mathrm{~min}$ at $95^{\circ} \mathrm{C}$ and chilled to $4^{\circ} \mathrm{C}$. Fluorescent PCR amplification products were analyzed by ABI PRISM 310 Genetic Analyzer with pop4 (Applied Biosystems, Foster City, CA, USA).

\section{Molecular analysis}

The CONVERT 1.31 software (Glaubitz 2004) was used to reformat files for the statistical analyses. Multilocus proportion of shared alleles (Dps) was computed between all possible mite pairs using the MICROSAT software (Minch 1997) ignoring preliminary clustering information; 10,000 datasets were generated by resampling the input data (bootstrapping). The Neighbor-Joining algorithm was used as implemented by the PHYLIP v. 3.6 Package (Felsenstein 1989), and a consensus dendrogram was obtained. The dendrogram was visualized using TreeIllustrator v. 0.52 Beta software format (Trooskens et al. 2005). The analysis of relationships among the different mite populations was improved by a simulation-based Bayesian assignment test. The test was carried out by the GENECLASS2 software (Piry et al. 2004). The probability of the multilocus genotype of any Iberian ibex-derived mites to be encountered in each of the skin subunits $\mathrm{H}, \mathrm{B}$, and $\mathrm{A}$ of the same individual animal was computed. The individual mites were assigned to that population for which the highest probability was obtained.

\section{Results and discussion}

Aiming to detect the possible S. scabiei skin-scale genetic diversity among three skin subpopulations (head, back, and abdomen subunits), $44 \mathrm{~S}$. scabiei mites were collected from the skin of three culled Iberian ibexes. Due to amplification and/or sequencing failure, the final analysis was based on 27 mites, nine from each animal. Of the nine ectoparasites, three were from each subunit $\mathrm{H}, \mathrm{B}$, and $\mathrm{A}$ (Table 1 and Fig. 1).

For all S. scabiei mites in this study, the number of alleles or locus on average was 3.20 ranging from 1 (Sarms 
44) to 6 (Sarms 36), the mean observed heterozygosity was 0.102 ranging from 0.038 (Sarms 33 and Sarms 37) to 0.25 (Sarms 36), and the mean expected heterozygosity was 0.284 ranging between 0.038 (Sarms 37) and 0.599 (Sarms 34).

The dendrogram, showing the proportion of shared alleles between pairs of individual mites from Iberian ibex Cp1, separated the mites of head subunit from mites of back and abdomen subunits (5607/10,000 bootstraps), while no clear separation was detected between mites from back and abdomen subpopulations (Fig. 2). Clear separation was detected in Iberian ibex Cp2, where mites from abdomen subunit were unambiguously clustered together (7911/10000 bootstraps), while the S. scabiei from head and back subpopulations were randomly distributed between two clusters (Fig. 3). Regarding Sarcoptes mites from C. pyrenaica Cp3, mites from back subpopulation were grouped in single cluster (5061/10,000 bootstraps), while the remaining ones from head and abdomen subunits were clustered randomly into two groups (Fig. 4).

Consequently, the dendrograms, showing the proportion of shared alleles between pairs of individual mites representing the three skin subpopulations (head, back, and abdomen subunits) from the individual Iberian ibexes, allowed the clustering of some mite samples up to their skin subunits. This skin-scale S. scabiei genetic structure did not have the same pattern in all the individual animals since mites were grouped together for the head in $\mathrm{Cp} 1$, for the abdomen in Cp2, and for the back in Cp3, which suggests interindividual differences in the colonization of the host skin by $\mathrm{S}$. scabiei. The skin-scale genetic structure would be explained by local colonization dynamics of S. scabiei after a single infestation due to, e.g., competition or avoidance processes (Kanno and Harris 2002). Another presumable explanation

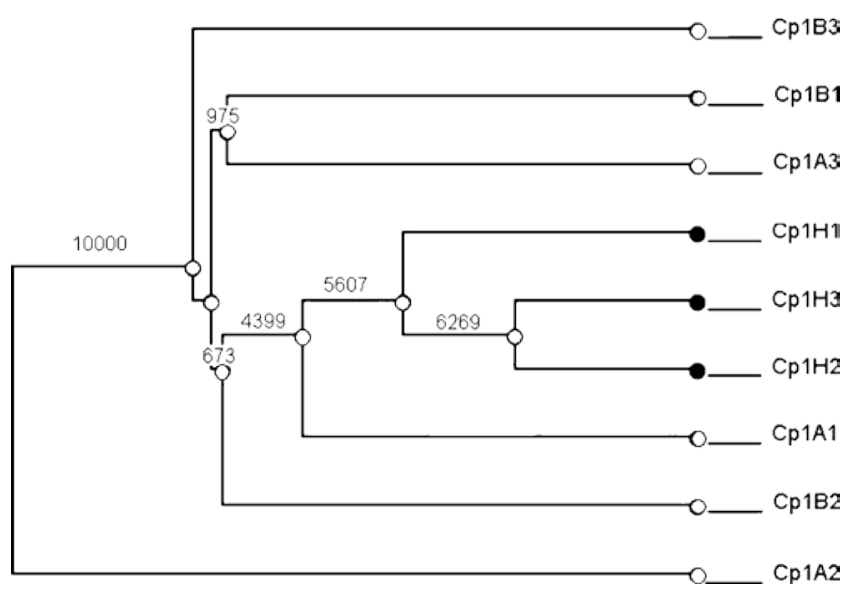

Fig. 2 Unrooted Dps consensus dendrogram for Sarcoptes scabiei from three skin subunits on the individual Cp1 of Iberian ibex. Numbers at the nodes are percentage values of 10,000 bootstraps supporting the same branching structure. Codes in this figure represent the sample codes in Table 1

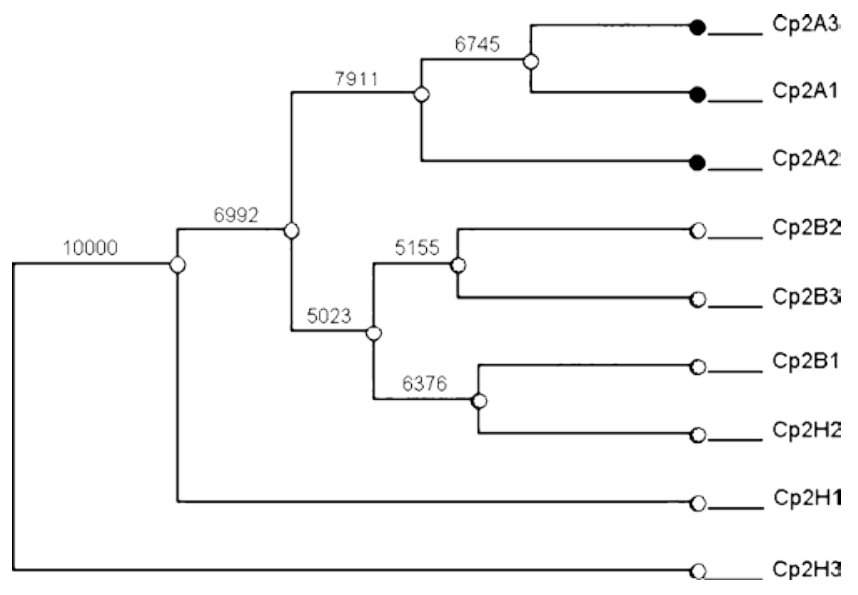

Fig. 3 Unrooted Dps consensus dendrogram for Sarcoptes mites from three skin subpopulations on the individual Cp2 of Iberian ibex. Numbers at the nodes are percentage values of 10,000 bootstraps supporting the same branching structure. Codes in this figure represent the sample codes in Table 1

could be that this skin-scale genetic structure would be the result of repeated infestations, especially taking into account that active infestation, residual skin reaction, and reinfestation are yet considered difficult to distinguish (Walton and Currie 2007). Further studies will, hence, be needed to test these hypotheses.

To our knowledge, this is the first record of skin-scale genetic structure among $\mathrm{S}$. scabiei from individual mangy animals. Despite the fact that the determining factors of this phenomenon remain to be explored, the observed skin-scale genetic structure has implications for studies on the population genetic diversity, life cycle, as well as for diagnosis and monitoring protocols of the ubiquitous Sarcoptes mite.

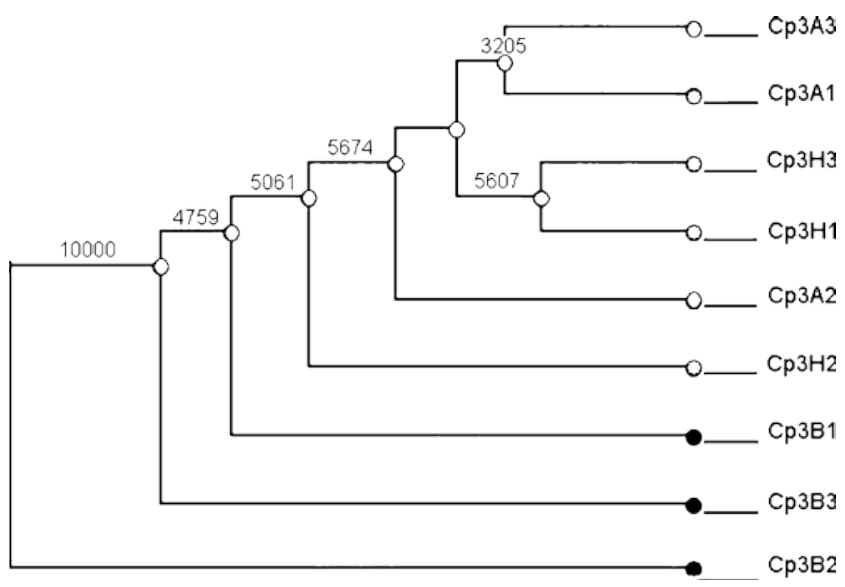

Fig. 4 Unrooted Dps consensus dendrogram for Sarcoptes scabiei from three skin subunits on the individual Cp3 of Iberian ibex. Numbers at the nodes are percentage values of 10,000 bootstraps supporting the same branching structure. Codes in this figure represent the sample codes in Table 1 
Acknowledgements The authors gratefully acknowledge the help of the guards of the hunting reserve of Sierra Nevada Natural Space, and RNM118 investigation group (Junta de Andalucía-Spain) for supporting SA's investigation stay in Italy. The study was supported by MURST contract year 2004, Prot. 2004078701001 (LR) and a grant by SCI Italian Chapter. XQZ was supported by a grant from the Program for Changjiang Scholars and Innovative Research Team in University, China (Grant No. IRT0723) and the Natural Science Foundation of Guangdong Province (Team Project, Grant no. 5200638). The experiments comply with the current laws of the countries in which the experiments were performed.

\section{References}

Alasaad S, Granados JE, Cano-Manuel FJ, Meana A, Zhu XQ, Pérez JM (2008a) Epidemiology of fasciolosis affecting Iberian ibex (Capra pyrenaica) in southern Spain. Parasitol Res 103:181-186

Alasaad S, Rossi L, Maione S, Sartore S, Soriguer RC, Pérez JM, Rasero R, Zhu XQ, Soglia D (2008b) HotSHOT Plus ThermalSHOCK, a new and efficient technique for preparation of PCRquality Sarcoptes mite genomic DNA. Parasitol Res (in press)

Berrilli F, D’Amelio S, Rossi L (2002) Ribosomal and mitochondrial DNA sequence variation in Sarcoptes mites from different hosts and geographical regions. Parasitol Res 88:772-777

Brimer L, Henriksen SA, Gyrd-Hansen N, Rasmussen F (1993) Evaluation of an in vitro method for acaricidal effect. Activity of parathion, phosmet and phoxim against Sarcoptes scabiei. Vet Parasitol 51:123-135

Burgess I (1994) Sarcoptes scabiei and scabies. Adv Parasitol 33:235292

Choe JC, Kim CK (1988) Microhabitat preference and coexistence of ectoparasitic arthropods on Alaskan seabirds. Can J Zool 66:987997

Clayton DH (1991) Coevolution of avian grooming and ectoparasite avoidance. In: Loye JE, Zuk M (eds) Bird-parasite interactions: ecology, evolution and behaviour. Oxford University Press, Oxford, pp 258-289

Coltman DW, Pilkington JG, Pemberton JM (2003) Fine-scale genetic structure in a free-living ungulate population. Mol Ecol 12:733-742

Coulon A, Guillot G, Cosson JF, Angibault JMA, Aulagnier S, Cargnelutti B, Galan M, Hewison AJM (2006) Genetic structure is influenced by landscape features: empirical evidence from a roe deer population. Mol Ecol 15:1669-1679

Crompton DWT (1997) Birds as habitat for parasites. In: Clayton DH, Moore J (eds) Host-parasite evolution: general principles and avian models. Oxford University Press, Oxford, pp 252-270

Fain A (1968) Étude de la variabilité de Sarcoptes scabiei avec une revisiondes Sarcoptidae. Acta Zool Pathol Antverp 47:1-196

Felsenstein J (1989) PHYLIP - Phylogeny inference package (Version 3.2). Cladistics 5:164-166

Glaubitz J (2004) CONVERT: A user-friendly program to reformat diploid genotypic data for commonly used population genetic software packages. Mol Ecol Notes 4:309-310

Gu XB, Yang GY (2008) A study on the genetic relationship of mites in the genus Sarcoptes (Acari: Sarcoptidae) in China. Int J Acarol 32:183-190

Hastings A, Cuddington K, Davies KF, Dugaw CJ, Elmendorf S, Freestone A, Harrison S, Holland M, Lambrinos J, Malvadkar U, Melbourne BA, Moore K, Taylor C, Thomson D (2005) The spatial spread of invasions: new developments in theory and evidence. Ecol Lett 8:91-101

Hughes C (1998) Integrating molecular techniques with field methods in studies of social behavior: a revolution results. Ecology 79:383-399
Kanno H, Harris MO (2002) Avoidance of occupied hosts by the Hessian fly: oviposition behaviour and consequences for larval survival. Ecol Entomol 27:177-188

León-Vizcaíno L, Ruíz de Ybáñez MR, Cubero MJ (1999) Sarcoptic mange in Spanish ibex from Spain. J Wildl Dis 35:647-659

Manel S, Schwartz MK, Luikart G, Taberlet P (2003) Landscape genetics: combining landscape ecology and population genetics. Trends Ecol Evol 18:189-197

Mellanby K (1944) The development of symptoms, parasitic infection and immunity in human scabies. Parasitology 35:197-206

Minch E (1997) http://hpgl.stanford.edu/projects/microsat/

Moritz C (1994) Defining 'evolutionarily significant units' for conservation. Trends Ecol Evol 9:373-375

Ochs H, Mathis A, Deplazes P (1999) Single nucleotide variation in rDNA ITS-2 differentiates Psoroptes isolates from sheep and rabbits from the same geographical area. Parasitology 119:419424

Pence DB, Ueckermann E (2002) Sarcoptic mange in wildlife. Rev Sci Tech Off int Epiz 21(2):385-398

Pérez JM, Ruíz-Martínez I, Granados JE, Soriguer RC, Paulino F (1997) The dynamics of sarcoptic mange in the ibex population of Sierra Nevada in Spain - influence of climatic factors. J Wildl Res 2:86-89

Pérez JM, Granados JE, Soriguer RC, Fandos P, Márquez FJ, Crampe JP (2002) Distribution, status and conservation problems of the Spanish ibex, Capra pyrenaica (Mammalia: Artiodactyla). Mammal Rev 32:26-39

Piry S, Alapetite A, Cornuet JM, Paetkau D, Baudouin L, Estoup A (2004) GENECLASS2: A software for genetic assignment and first-generation migrant detection. J Hered 95:536-539

Ross KG (2001a) Molecular ecology of social behaviour: analyses of breeding systems and genetic structure. Mol Ecol 10:265284

Ross KG (2001b) How to measure dispersal: the genetic approach. The example of fire ants. In: Clobert J, Danchein E, Dhondt AA, Nichols JD (eds) Dispersal. Oxford University Press, Oxford, pp 29-42

Soglia D, Rasero R, Rossi L, Sartore S, Sacchi P, Maione S (2007) Microsatellites as markers for comparison among different populations of Sarcoptes scabiei. It J Anim Sci 7:214-216

Storfer A, Murphy MA, Evans JS, Goldberg CS, Robinson S, Spear SF, Dezzani R, Delmelle E, Vierling L, Waits LP (2007) Putting the 'landscape' in landscape genetics. Heredity 98:128-142

Sugg DW, Chesser RK, Dobson FS, Hoogland JL (1996) Population genetics meets behavioral ecology. Trends Ecol Evol 11:338-342

Trooskens G, De Beule D, Decouttere F, Van Criekinge W (2005) http://nexus.ugent.be/geert/

Walton SF, Currie BJ (2007) Problems in diagnosing scabies, a global disease in human and animal populations. Clin Microbiol Rev 20:268-279

Walton SF, Currie BJ, Kemp DJ (1997) A DNA fingerprinting system for the ectoparasite Sarcoptes scabiei. Mol Biochem Parasitol 85:187-196

Walton SF, Choy JL, Bonson A, Valle A, McBroom J, Taplin D, Arlian L, Mathews JD, Currie B, Kemp DJ (1999) Genetically distinct dog-derived and human-derived Sarcoptes scabiei in scabies-endemic communities in northern Australia. Am J Trop Med Hyg 61:542-547

Walton SF, Holt DC, Currie BJ, Kemp DJ (2004) Scabies: New future for a neglected disease. Adv Parasitol 57:309-376

Wright S (1978) Evolution and the genetics of populations, Vol. IV: Variability within and among natural populations. University of Chicago Press, Chicago

Zahler M, Essig A, Gothe R, Rinder H (1999) Molecular analyses suggest monospecificity of the genus Sarcoptes (Acari: Sarcoptidae). Int J Parasitol 29:759-766 